\title{
Investing in new services is key
}

An editing error occurred in this Letter by Claire Hilton (BMJ 2012;344:e2746, doi:10.1136/bmj.e2746). The last sentence of the third paragraph should read: "The plan to encourage the creation of 20 'dementia friendly communities,' where individuals, businesses, and the state work together to support people with dementia seems yet another way to move government health service provision on to the communities [not "into the community"]."

Cite this as: BMJ 2012;344:e3036

๑ BMJ Publishing Group Ltd 2012 